\title{
The effect of uncertainty on learning in game-like environments
}

\author{
Erol Ozcelik ${ }^{\mathrm{a}, *}$, Nergiz Ercil Cagiltay ${ }^{\mathrm{b}}$, Nese Sahin Ozcelik ${ }^{\mathrm{c}}$ \\ ${ }^{a}$ Department of Computer Engineering, Atilim University, Ankara 06836, Turkey \\ ${ }^{\mathrm{b}}$ Department of Software Engineering, Atilim University, Ankara 06836, Turkey \\ ${ }^{\mathrm{c} C o m p u t e r}$ Technology and Information Systems, Bilkent University, Ankara 06800, Turkey
}

\section{A R T I C L E I N F O}

\section{Article history:}

Received 3 July 2012

Received in revised form

13 February 2013

Accepted 14 February 2013

\section{Keywords:}

Interactive learning environments

Post-secondary education

\begin{abstract}
A B S T R A C T
Considering the role of games for educational purposes, there has an increase in interest among educators in applying strategies used in popular games to create more engaging learning environments. Learning is more fun and appealing in digital educational games and, as a result, it may become more effective. However, few research studies have been conducted to establish principles based on empirical research for designing engaging and entertaining games so as to improve learning. One of the essential characteristics of games that has been unexplored in the literature is the concept of uncertainty. This study examines the effect of uncertainty on learning outcomes. In order to better understand this effect on learning, a game-like learning tool was developed to teach a database concept in higher education programs of software engineering. The tool is designed in two versions: one including uncertainty and the other including no uncertainty. The experimental results of this study reveal that uncertainty enhances learning. Uncertainty is found to be positively associated with motivation. As motivation increases, participants tend to spend more time on answering the questions and to have higher accuracy in these questions.
\end{abstract}

(c) 2013 Elsevier Ltd. All rights reserved.

\section{Introduction}

One of the serious problems in education is the failure of schools to motivate students (Lepper, Sethi, Dialdin, \& Drake, 1997). Learning tasks in schools have been criticized to be boring, too easy, or decontextualized (Miller \& Backman, 2004; Salomon \& Perkins, 1998). In order to motivate students, serious games have been used for educational purposes for decades. Considering this potential of games, educators have been keen on creating more game-based learning environments (Dickey, 2005). In addition, computer and video games are suggested to increase the motivation and engagement of players because they include elements such as play, fantasy, curiosity, challenge, competition, cooperation, and learner-control (Barab, Thomas, Dodge, Carteaux, \& Tuzun, 2005; Cordova \& Lepper, 1996; Malone, 1981). However, insufficient research has been conducted to examine the effect of these individual elements on motivation and learning. One of the features of games that has yet remained unexplored is uncertainty (Howard-Jones \& Demetriou, 2009). Studies in the literature show that uncertainty increases the level of engagement (Howard-Jones \& Demetriou, 2009). Nevertheless, to our knowledge, no study has examined the impact of uncertainty on learning and the causal relationship between uncertainty and learning outcomes. For this reason, this study attempts to better understand this effect on learning in game-based environments. In the following section, literature review on games, flow theory, motivation, indicators of motivation in game-based learning, and uncertainty are covered.

\section{Literature review}

A game is defined as a rule-based system having quantifiable outcomes which are assigned to specific values (Juul, 2005). The player spends effort to influence the outcomes in the game, and as a result, the player will be happy with positive outcomes or unhappy with negative outcomes (Juul, 2003). Meaningful learning occurs when the relationships between actions of a player and the outcomes of the system in a game are "discernable and integrated into the larger context of the game" (Salen \& Zimmerman, 2004, p. 34).

\footnotetext{
* Corresponding author. Tel.: +90 312586 8793; fax: +90 3125868091.

E-mail address: eozcelik@atilim.edu.tr (E. Ozcelik).
} 
Many studies in the literature have shown that games can increase motivation (e.g., Kebritchi, Hirumi, \& Bai, 2010; Papastergiou, 2009; Prensky, 2003; Randel, Morris, Wetzel, \& Whitehill, 1992; Rosas et al., 2003; Schwabe \& Göth, 2005), engagement (e.g., Barab, Pettyjohn, Gresalfi, Volk, \& Solomou, 2012; Parker \& Lepper, 1992), and learning (e.g., Terrell \& Rendulic, 1996). Games have been proposed to provide a more effective learning by bringing about more fun, appealing, and learner-centered environments (Ebner \& Holzinger, 2007; Prensky, 2001). Several reasons have been suggested to account for the positive effect of games on learning. One is that, in order to move to higher levels of play, games require individuals to use prior knowledge, transfer new information into new situations, apply information in correct contexts, and learn from immediate feedback (Oblinger, 2004). Studies have shown that games help learners apply, synthesize, and think critically about what they learn through active and social participation (Colby \& Colby, 2008; Fu, Su, \& Yu, 2009; Koster, 2005). Gamebased environments afford activities for experiential, situated, problem-based, and active learning (Boyle, Connolly, \& Hainey, 2011).

One of the reasons for individuals preferring to learn through games may be their optimal flow experiences and their motivation on playing games (Squire, 2003). While playing games people usually spend considerably longer time-periods on the subject of the game. They tend to enjoy the environment and have higher levels of motivation to remain in such environments. This concept has been elaborated by researchers of the flow theory. Csikszentmihalyi (1993) defines flow as 'a state of consciousness that is sometimes experienced by individuals who are deeply involved in an enjoyable activity'. When people are in the optimal flow experience, they are in such a psychological state that, during the activity, they do not care about their environment (Inal \& Cagiltay, 2007; Kiili, 2005). Players also temporarily lose track of time, surroundings, and the actual environment that they are in. Studies show that participants perceive higher levels of flow, and apply in-depth problem solving strategies with computer games (Liu, Cheng, \& Huang, 2011). In order to put players in the flow zone during games, game designers and developers mainly focus on improving the motivation and the attention level required for games (Csikszentmihalyi, 1993). Several studies propose guidelines for creating flow in games (Andresen \& Ahdell, 2002; Colby \& Colby, 2008; Csikszentmihalyi, 1975, 1993; Ellis, Voelkl, \& Morris, 1994; Hong et al., 2009; Kiili, 2005; Koster, 2005; Northrup, 2001; Pilke, 2004; Price, Rogers, Scaife, Stanton, \& Neale, 2003; Sweetser \& Wyeth, 2005). These studies suggest that there exists a relationship between learning and excitement or flow in games.

According to researchers, motivation is a preliminary step in the instructional process (Chan \& Ahern, 1999). As an important factor for increasing level of flow and learning in games, the Attention, Relevance, Confidence, and Satisfaction (ARCS) model of motivation identifies these four aspects to be addressed in order to increase motivation (Keller, 1987). To begin with, and, as the first element of motivation, attention should be drawn to the relevant stimuli and sustained during the course of instruction. Interesting animations or graphics, events that present conflict or incongruity, or unresolved problems can build curiosity and attract attention (Keller, 2008). "After gaining attention and building curiosity, a challenge is to sustain them, which can be done by applying the principle of variability. People adapt to routine stimuli; no matter how interesting a given technique or strategy is, they will lose interest over time" (Keller, 2008, p.177). The second element, relevance, is associated with whether learning activities are perceived to be related to the students' goals, learning styles, and prior experiences. To this end, teachers should discover their learners' interests and needs and incorporate them into their instructions (Keller, 1987). The third factor, confidence, is the level of the students' confidence and expectancy to be successful. For this, instruction should be designed so that success is attainable with realistic effort and ability. Satisfaction, as the last element, refers students' anticipation and experience of positive feelings about the outcomes of the current learning task (Keller, 2008). To accomplish this, intrinsic and extrinsic reinforcements should be provided in learning environments.

In addition, some measures have been used in the related literature to assess motivation in game-based learning. For instance, learners' performance while playing a game is an essential indicator of the players' engagement during a game. When players get higher scores, their post-test scores also increase, which shows that scores of players in games (accuracy) may be used as a predictor for their learning (Shin, Arbor, \& Soloway, 2006). As Garris, Ahlers, and Driskell (2002) report, performance feedbacks and scores in games allow players to track their own progress toward the desired goals. Anecdotal evidence by Toups, Kerne, and Hamilton (2009) suggests that there is a relation between game score and motivation. They propose that game scores intrinsically motivate, engage, reward the player and direct action.

Furthermore, players' on-task time (i.e., the time spent on the learning material) during the game is another indicator of motivation (Beck, 2004). Studies show that there is a relationship between individuals' response time and their motivation or engagement in learning. When participants spend a reasonable amount of time to response a question, this indicates that they are feeling more responsible for their own learning and that they are more motivated. Whereas, when their responses are quick, this is a sign of disengagement in learning and lack of motivation (Beck, 2004).

One of the factors that have a potential impact in increasing level of flow and motivation in games and as such, improving learning progress is uncertainty. Uncertainty is determined by the probability $P$, that an event will occur, "being maximal at $P=0.5$ and decreasing at higher and lower probabilities" (Fiorillo, Tobler, \& Wolfram Schultz, 2003, p. 1898). Anselme (2010) has shown that uncertain events can motivate individuals. The release of dopamine, a neurotransmitter which is associated with reward-seeking behavior (Arias-Carrión \& Pöppel, 2007) increases as the uncertainty of stimulus-reward relationship is increased. Dopamine neurons in the brain are activated by rewarding stimuli, such as food, sex, music, and video games (Cannon \& Bseikri, 2004). Howard-Jones and Demetriou (2009) investigated the effect of gaming uncertainty on learning and discovered that players preferred the uncertain, rather than the certain option of the game. Moreover, they found that participants in the uncertain condition experienced higher arousal as measured by electrodermal activity. In addition, Howard-Jones, Demetriou, Bogacz, Yoo, and Leonards (2011) showed that a reward-based model of dopaminergic activity could predict the recall performance of subjects. Howard-Jones and Demetriou (2009) also report that gaming uncertainty may improve engagement and may also improve encoding and later recall. It has been suggested that uncertainty deepens the players' interest in a game (Hong et al., 2009), hence, it may play an important role in learning through playing. Whitehall and McDonald (1993) showed that varying payoff in a game increases the persistence of learners in choosing more difficult levels and game performance. Hence, uncertainty (Hong et al., 2009) is an important factor that may affect the flow in games and which has not been studied in detail as far as the available literature is concerned.

Although several studies have shown that games improve learning, there do not exist many examples of such games in higher education, especially in the field of computer engineering. Additionally, the guidelines for developing such educational games are very limited. On the other hand, students in higher education prefer to use computer simulations and games in their lessons (Cagiltay, 2007; Tao, Cheng, \& Sun, 2009). Accordingly, this study aims to better understand the effect of uncertainty on learning through games. In order to examine this, a 
game-like learning environment is developed to teach some concepts on Entity-Relationship Diagrams (ERD), which is a main database design tool in relational database systems. Two versions of the learning environment were developed. One included uncertainty and the other included no uncertainty.

\section{Research methodology}

\subsection{Participants}

Participants of this study were 140 (38 female and 102 male) undergraduate students from computer engineering, software engineering, and information systems engineering departments in Atilim University with an age ranging from 18 to 28 ( $M=21.80$, SD $=1.58)$. The participants were randomly assigned to either the uncertain group $(n=71)$ or the certain group $(n=69)$. They voluntarily participated in this experiment for extra course credit.

\subsection{Materials}

\subsubsection{Prior knowledge test}

The prior knowledge test is a self-rating database knowledge scale containing five statements (e.g., 'the difference between one-to-one and one-to-many relations', 'the concept of cardinality in database relations') in which participants were requested to mark a five-point scale ( $1=$ 'I know very little', $5=$ 'I know very much'). Similar self-reported scales were frequently used in other research studies (Meyer, Rasch, \& Schnotz, 2010; Moreno \& Mayer, 1999).

\subsubsection{Post-test}

The post-test included 6 questions. The first one was a matching question, in which students were given an ER diagram and were asked to identify the concept name of the element on the diagram. For instance, they needed to match the item 'play' on the figure with the concept name 'entity'. The second and third questions were fill-in-the-blank type in which the participants were given an ER diagram and requested to fill in the blanks with appropriate concept names. A sample item is 'The address is a (n)............' where the answer is 'attribute'. The fourth and fifth questions had a true-false test item format. The individuals were asked to evaluate whether the written statements were true or false with respect to the given ER diagram. In order to correct for guesses, the number of incorrect answers is subtracted from the number of correct answers in true-false questions. The students were also informed about the penalty of incorrect responses so as to further minimize the guessing factor. The matching, fill-in-the-blank and true-false type questions had 5, 8, and 16 items, respectively. In the last question, students were provided with data requirements of a simple case and were required to draw the ER diagram of it.

\subsubsection{Instructional materials motivation survey}

The motivation of students during the game was assessed by a Turkish version (Acar, 2009) of the Instructional Materials Motivation Survey (IMMS) (Keller, 1993). The survey included 36 items using a 5-point Likert-type response scale ( $1=$ 'completely not true', 5 = 'completely true') with four subscales: attention, relevance, confidence, and satisfaction in accordance with the ARCS Model (Keller, 1983).

\subsection{The game-like learning environment}

The game-like learning tool was presented in Turkish. Once an individual started the computer-based application, an agent ID was assigned to that person and they were all expected to use this ID in further documents that they would fill. The main goal of the game was to collect 336 points and the plot was as follows: There has been an attack through seven entrances to the nation's database center containing high profile and intelligence information. In order to block these doors and secure the database system, the players were expected to find

Table 1

Concepts covered in the computer-based application and the associated secret symbols.

\begin{tabular}{|c|c|c|}
\hline Door & Concept & Secret symbol \\
\hline 1 & Entity, relationship & $\square . \infty$ \\
\hline 2 & Attribute, key attribute & $0 . \ominus$ \\
\hline 3 & Cardinality - Many & $\geqslant \notin$ \\
\hline 4 & Cardinality - One & $H+H$ \\
\hline 5 & Participation - Partial & $\theta$ \\
\hline 6 & Participation - Total & + \\
\hline \multirow[t]{3}{*}{7} & $\begin{array}{l}\text { Relationship types } \\
\text { many to many }\end{array}$ & $\Rightarrow$ and $\&$ \\
\hline & one to one & $1+$ and $H$ \\
\hline & one to many & $H$ and $\&$ \\
\hline
\end{tabular}


and understand secret symbols, which are, in fact, the actual concepts the game aims to teach. Table 1 shows the relationship between the concepts that are the objectives of the game and the secret symbols that need to be understood as well as their distribution among the seven conceptual doors.

The participants were given 21 true-false questions (three questions for each door symbol). These questions help the participants to grasp the meaning of each symbol by providing feedback upon their response. Once users understand these secret symbols and collect 336 points from the game, they will be able to secure the attacked doors of the database center.

When the computer-based application started, the students needed to roll the two dice by clicking on the related button (see Fig. 1). Afterwards, a question including a statement and an ER diagram appeared on the screen. The participants were asked to read the statement and decide whether it was true or false with respect to the given diagram. Half of the statements were true. The participants gave their responses by selecting a radio button. After responding to the statement and clicking the OK button, a feedback was presented indicating if the response was correct or not along with an explanation for the answer. The participants were warned to carefully read these explanations in order to become more successful for the upcoming questions and better understand the secret symbols. Moreover, each feedback included the points that the participant gained or lost from the question.

For each correct response, the participants would collect ten points and the total value of the dice. For example, as to the question illustrated in Fig. 1, since the student's response is correct, s/he gets 10 points plus 5 points, which is the total value of the dice. The students lost as many points as the total value of the dice if their responses were incorrect. On the other hand, if both dice were one, then the student would lose all the collected points (Howard-Jones \& Demetriou, 2009). After the feedback, the users could continue the play and see the next statement by pressing the arrow button.

For each player, two time values were calculated and logged in the database of the application: the response time and the time spent reading the descriptions. The former is the duration between the time stamps when the player clicks the dice button until he or she responds to the question. During this time period, the player reads the statement and provides response to that question, and finally pushes to the OK button to see the system's feedback on his/her response. The latter value is calculated as the time between the onset of the feedback message and the press of the arrow button to see the next question.

The game-based learning environment was presented in two versions, as in Howard-Jones and Demetriou's (2009) study. The uncertain version is the one which assigns random dice values each time the player hits the dice. On the other hand, the certain version yields dice throw of double 3 without any random assignment. In other words, both versions of the computer-based application have the same content

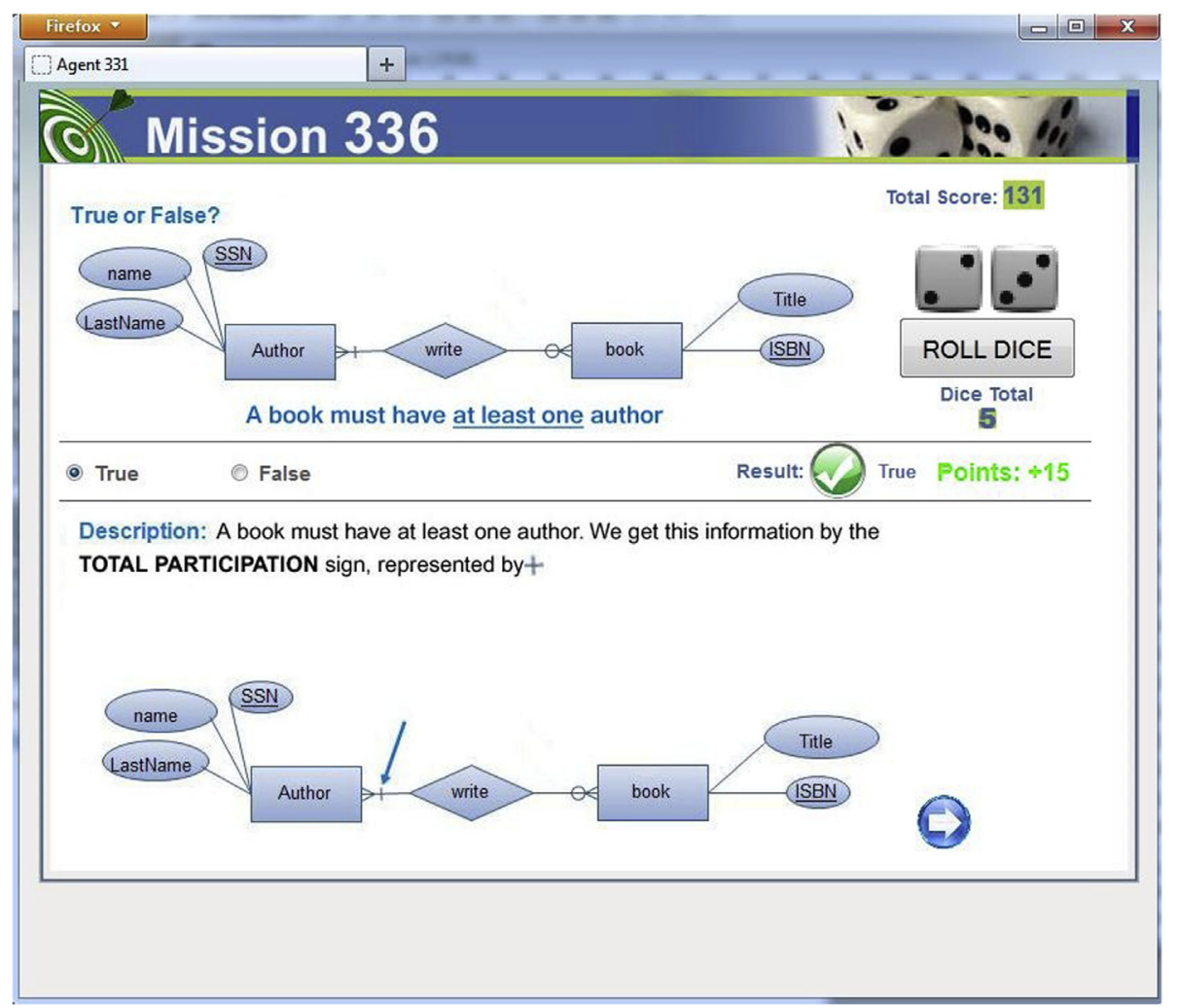

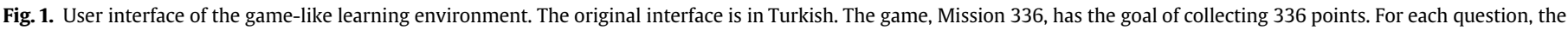

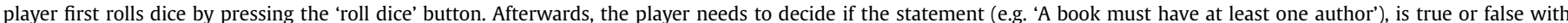

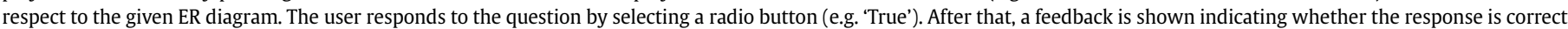

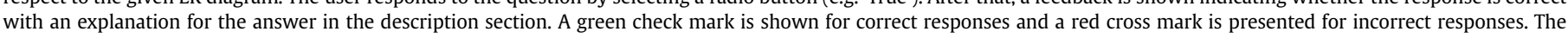

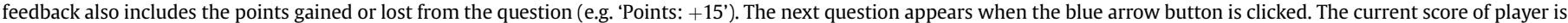

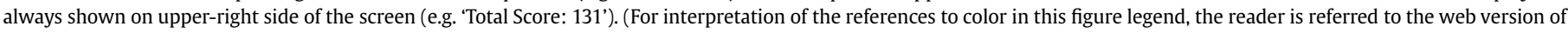
this article.) 
as well as the user interface, except for the values of the dice. In the uncertain version, there is an uncertainty in the assignment of the dice values. On the other hand, in the other version of the application, there is no uncertainty.

\subsection{Procedure}

The participants were tested in groups of 11-19 in a computer laboratory. The participants were randomly assigned to either the uncertain version or the certain version of the application, hence called 'uncertain' or 'certain' groups, respectively. First they were given a short questionnaire regarding their demographic information and the prior knowledge test. Afterwards, participants were given necessary information about the goals, rules, and the awards of the game-like learning environment. They were told that the highest scorer would win a surprise gift (i.e., a USB memory stick). To familiarize subjects with the environment, all underwent a short training session. After playing the computer-based application, they were given the IMMS and the post-test. No time limitation was applied for playing in the game-like environment and for answering the post-test.

\subsection{Research model and hypotheses}

The research model (see Fig. 2) based upon the supporting evidence (see Table 2) illustrates the hypothesized cause and effect relationships between the variables of uncertainty, motivation, and learning outcomes. In this study, the learners' game score, reflecting their performance during the play is referred to as accuracy. The accuracy values are calculated by the application itself, while the response time is regarded as the average duration that the player spends for reading the statement and providing the response for it.

\section{Results}

In order to examine whether the uncertain group and the certain group differed in terms of their prior knowledge of the concept of database, an independent samples $t$-test was conducted. According to Levene's test, the homogeneity of variance assumption of the $t$-test was not met, $p=0.05$. For this reason, Welch's $t$ test, which assumes unequal variances between the two groups, was administered. This test showed that there was no significant difference in prior knowledge of the groups, $t(127)=1.20, p=0.23$. A separate independent samples $t$ test was run to compare the post-test scores of the uncertain and certain groups. Once again, Levene's test indicated that the homogeneity of variance assumption of the $t$-test was not achieved, $p=0.01$. Whereas, Welch's $t$-test showed that the uncertain group performed significantly better than the certain group in the post-test, $t(133)=2.58, p=0.01$ (see Table 3 ). The effect size was small (Cohen's $d=0.20$ ). The better post-test scores of the uncertain group may be due their higher prior knowledge. An analysis of covariance (ANCOVA) was performed on the post-test scores, adjusting for the initial difference in prior knowledge. The effect of the group remained significant, $F(1,134)=5.46, p=0.02$, suggesting that the effect of uncertainty on the post-test existed even after controlling for the differences in the prior knowledge between the groups.

A separate independent samples $t$-test was run to assess the effect of group on total reading time of explanations and total response time of questions in the game-like learning environment. It was found that the group effect was not significant on total reading time of explanations, $t(138)=0.40, p=0.69$ and the total response time to questions, $t(138)=1.35, p=0.18$. In addition, there was no significant difference in motivation between the groups, $t(138)=-0.60, p=0.55$. Moreover, statistically there was no difference between the two groups in terms of accuracy, $t(138)=1.33, p=0.19$.

It should be pointed out that failure to find significant effects of the group on the above stated measures may be due, in part, to the high variance level that existed among each individual variable. For this reason, Pearson correlation analyses were performed (see Table 4 for zero-order correlations). The higher total response time to the questions, accuracy, and motivation were correlated with higher post-test scores. However, the correlation between the total reading time of explanations and the post-test found not to be statistically significant. Higher total response time to the questions and accuracy were associated with higher total reading time of explanations. There was no significant correlation between motivation and the total reading time of the explanations. Higher motivation scores, but not higher accuracy was related to higher total response time to the questions. Lastly, motivation was positively correlated with accuracy.

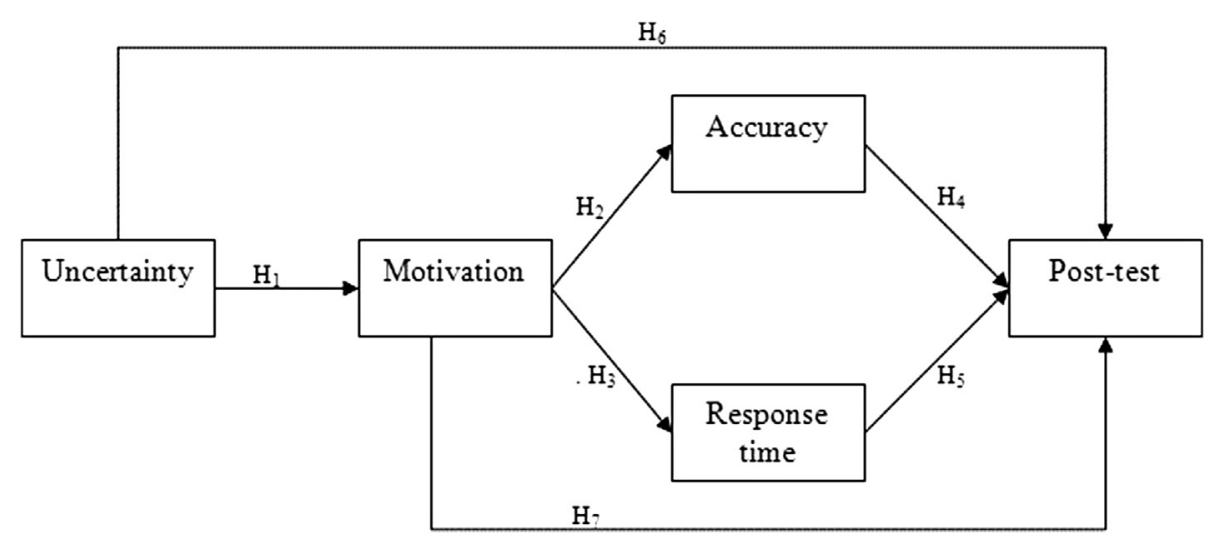

Fig. 2. The causal structure of the hypothesized research model for the relationship between uncertainty, motivation, accuracy, response time, and post-test. 
Table 2

Hypotheses and supporting evidences.

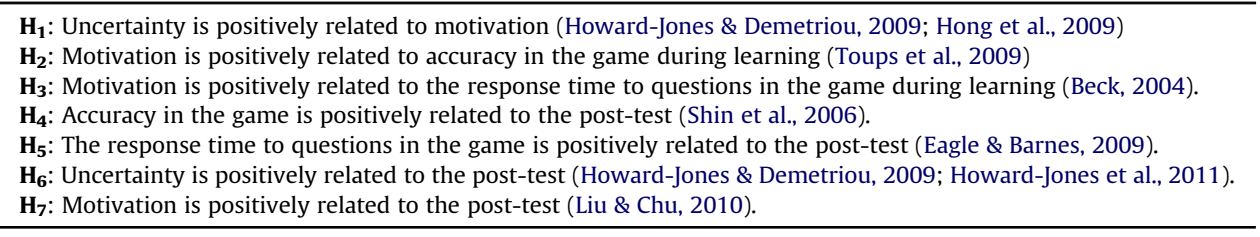

Table 3

Mean scores and standard deviations for uncertain and certain groups on prior knowledge test and post-test.

\begin{tabular}{lllll}
\hline & Prior knowledge & & \multicolumn{2}{c}{ Post-test } \\
\cline { 2 - 4 } Group & $M$ & SD & M & 22.74 \\
\hline Uncertain & 7.36 & 4.39 & 9.76 \\
Certain & 6.56 & 3.36 & 18.91 & 7.74 \\
\hline
\end{tabular}

The proposed model was tested by a path analysis using LISREL 8.8 (Jöreskog \& Sörbom, 1997). The results of the path analysis showed adequate model-to-data fit as reflected in the following fit indices: Goodness-of-Fit Index (GFI) $=0.95$, the Comparative Fit Index $(\mathrm{CFI})=0.92$, and the Standardized Root Mean Square Residuals (SRMR) $=0.05$.

As seen in Fig. 3, the squared multiple correlations revealed that $20 \%$ variance in the post-test was accounted for by the model. The standardized parameter estimates are presented in Fig. 3. As shown, uncertainty was positively associated with motivation $(t=1.29)$. Thus, $\mathrm{H} 1$ was supported. Motivation was positively related with accuracy $(t=3.82)$ and the response time to the questions $(t=2.23)$, therefore, H2 and H3 were supported. The post-test was positively associated with accuracy $(t=3.75)$, response time $(t=2.55)$, uncertainty $(t=2.17)$, and motivation $(t=1.29)$, all of which support $\mathrm{H} 4, \mathrm{H} 5, \mathrm{H} 6$, and $\mathrm{H} 7$, respectively.

\section{Discussions and conclusion}

The main goal of this study was to investigate the effect of uncertainty on learning in game-like environments. A computer-based application was designed in two versions: the uncertain and the certain one. The experimental results of this study showed that the uncertainty group outperformed the certain group, confirming that the element of uncertainty enhanced learning in the game-like environment. These findings support the predictions of Howard-Jones and Demetriou (2009). To our knowledge, this is the first study demonstrating that uncertainty improves learning outcomes by means of game-like environments. Howard-Jones and Demetriou (2009) neither use any scale to measure the motivation among their participants nor demonstrate whether uncertainty enhances learning. Nonetheless, they found that participants who played the uncertain version of the game experienced higher arousal, which was evident by stronger electrodermal responses. Supporting their findings, the current study adds that there exists a positive relation between uncertainty in a game-like environment and the motivation among its players.

The effect of uncertainty on motivation, response time to the questions, and reading time of the explanations to the answers of those questions were not statistically significant. However, this might be due to the high variance among these dependent variables. When correlation analyses were performed, it was found that higher motivation, response time, and accuracy were associated with higher posttest performance levels among the learners. Higher response time and accuracy to questions were associated with higher reading time of the explanations. There were also positive correlations between motivation and the reading time of the explanations. The correlation between motivation and accuracy was found to be both significant and positive.

In order to model causal relationships between these observed variables, a path analysis was conducted (Raykov \& Marcoulides, 2006). Instead of administering several correlations or regressions, we examined whether our hypothesized model based on previous research adequately fit the data. Consistent with prior studies (Hong et al., 2009; Howard-Jones \& Demetriou, 2009), the results of the path analysis reveal that uncertainty is positively associated with the motivation of learners. The more motivated they were, the more time they tended to spend on answering the questions in the game-like environment and to have higher accuracy in these questions, as suggested by Beck (2004) and Toups et al. (2009). As a result of high motivation (Liu \& Chu, 2010), uncertainty (Howard-Jones \& Demetriou, 2009; Howard-Jones et al., 2011), accuracy (Shin et al., 2006), and response time (Eagle \& Barnes, 2009), the learners performed better in the posttest.

Table 4

Zero-order correlations for post-test, motivation, and behavioral measures.

\begin{tabular}{|c|c|c|c|c|c|}
\hline Variable $^{\mathrm{a}}$ & 1 & 2 & 3 & 4 & 5 \\
\hline 1. Post-test & - & & & & \\
\hline 2. Total reading time of the explanations & 0.10 & - & & & \\
\hline 3. Total response time to the questions & $0.27^{* *}$ & $0.28^{* *}$ & - & & \\
\hline 4. Accuracy & $0.37^{* *}$ & $.018^{*}$ & 0.11 & - & \\
\hline 5. Motivation & $0.22^{* *}$ & -06 & $0.19^{*}$ & $0.31^{* *}$ & - \\
\hline
\end{tabular}

${ }^{*} p<0.05 ;{ }^{* *} p<0.01$

a $n=140$. 


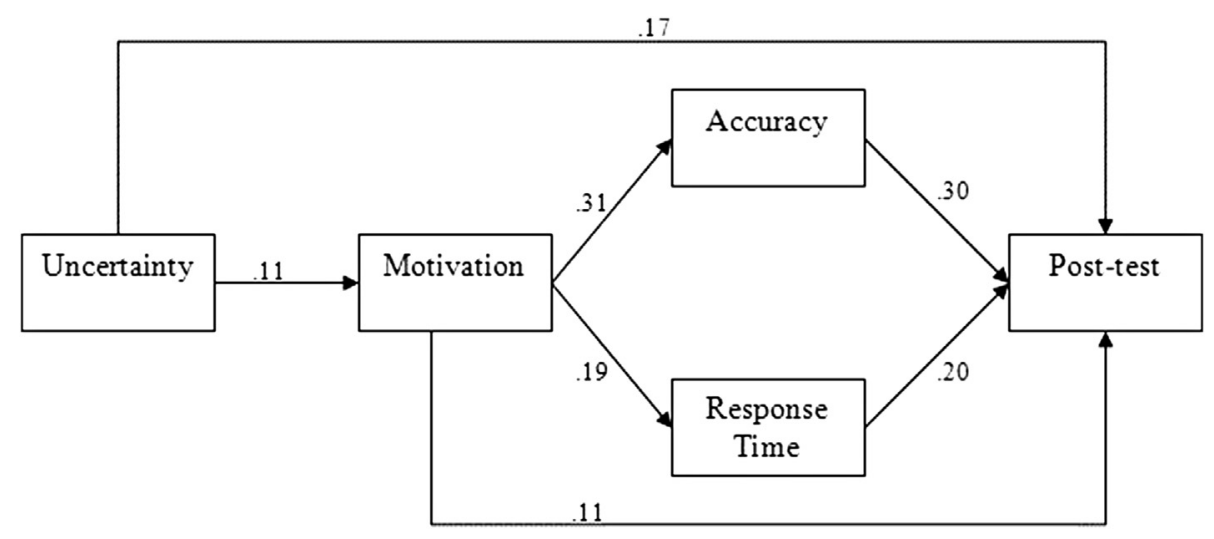

Fig. 3. Results of the tested model with standardized path coefficients.

Howard-Jones and Demetriou (2009) examined the effect of uncertainty on learning factual information. However, the participants of this study needed to both recall the meaning of the symbols in the ER diagrams and evaluate whether the given statement (e.g. 'A book must have at least one author') was true or false with respect to the ER diagram. In addition, the participants needed to apply their knowledge by drawing an ER diagram by themselves for a novel case in the post-test. For these reasons, the findings of the current study provide evidence for the effect of uncertainty on deep learning (Howard-Jones \& Demetriou, 2009). More research studies should be conducted to investigate this issue.

Our results confirm the game model of Garris et al. (2002) which asserts that game features influence user reactions and behavior in the game such as increased interest, enjoyment, and involvement. Consequently, these behaviors affect learning outcomes. In line with this model, we found that uncertainty as an important game feature caused a tendency among the participants toward devoting more time to answering the questions and thus, performing better in the play. When game-like environments include essential features such as uncertainty, challenge, curiosity and player control, they may improve learning. On the other hand, when games are not fun, engaging, or challenging, games are not helpful (Villalta et al., 2011).

The results of the present study can also help us to understand why playing games can become addictive (Griffiths \& Davies, 2002). Psychological studies have shown that uncertain events induce an increase in the release of the dopamine (e.g. Arias-Carrión \& Pöppel, 2007). Dopamine is implicated in addictive behavior (Koob, 1992). As a result, the addictiveness of games may be related to the release of dopamine when the outcomes are uncertain. Chance-based uncertainty is regarded among educators as a factor to be eliminated from learning environments (Howard-Jones et al., 2011). Moreover, it has been suggested that playing video games frequently during childhood or adolescence may give rise to pathological gambling tendencies in adulthood (Griffiths, 1999). However, little evidence exists showing adverse effects of excessive play (Griffiths, 2005).

The effects of uncertainty on learning may be influenced by gender. For instance, women compared to men were found to be more averse to risk and uncertainty in all domains except social risk (Weber, Blais, \& Betz, 2002). Consistent with this finding, another study showed that females have less risky preferences than females in a ring-toss game (Sorrentino, Hewitt, \& Raso-Knott, 1992). Due to the unbalanced sample size of 38 female and 102 male participants, the effect of gender was not analyzed in the current study. Future research should investigate this issue further by incorporating a balanced and a large sample size of male and female participants.

Generally, instructional activities in classrooms are not interesting or motivating for learners (Cordova \& Lepper, 1996). When instruction is presented in a decontextualized or abstract form, the intrinsic motivation of students decreases (Lave, 1998). Hence, educators need tools to keep intrinsic motivation higher through aids such as games. However, there is a misconception among educators that play is irrelevant to learning (Rieber, 1996). Besides, playing violent games is found to be associated with aggressive behavior (Anderson, 2004). On the other hand, students of the new generation who possesses extensive experiences with computer and video games prefer game-based learning (Prensky, 2001). Studies have shown that games are effective tools to motivate students and improve their learning (e.g. Lepper \& Cordova, 1992). Thus, many researchers argue that games should complement conventional lectures (Tan, Tse, \& Chung, 2010; Torrente, Moreno-Ger, Martínez-Ortiz, \& Fernandez-Manjon, 2009).

The results of this study are very important for guiding the educational designers to create more effective game-like learning environments. Additionally instructors can also use these results to better organize their course curricula. The learning environment in games should be intrinsically motivated for players (Hainey, Connolly, Stansfield, \& Boyle, 2011). By using design factors, such as uncertainty, the positive effect of game-like environments can be improved. If sound principles to improve level of engagement and entertainment in games are established, we can create better game-based learning environments (Kiili, 2007; Moreno \& Mayer, 2005). Moreover, this study supports that game-like learning tools can be beneficial in higher education. Such tools can be used as supportive tools in the classical educational environments as well as in other educational programs including distance education.

\section{References}

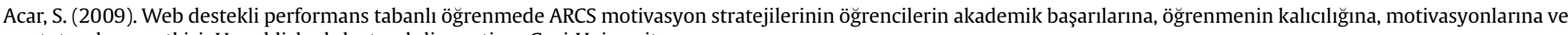
tutumlarına etkisi. Unpublished doctoral disseration, Gazi University.

Anderson, C. A. (2004). An update on the eVects of violent video games. Journal of Adolescence, 27, 113-122.

Andresen, G., \& Ahdell, R. (2002). Games simulation in corporate e-learning. Master thesis of University of Illinois.

Anselme, P. (2010). The uncertainty processing theory of motivation. Behavioural Brain Research, 208, 291-310.

Arias-Carrión, O., \& Pöppel, E. (2007). Dopamine, learning and reward-seeking behavior. Acta Neurobiologiae Experimentalis, 67(4), 481-488. 


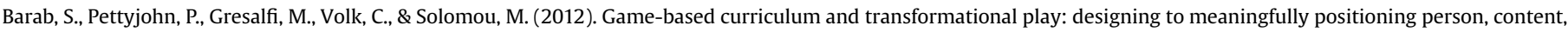
and context. Computers \& Education, 58(1), 518-533.

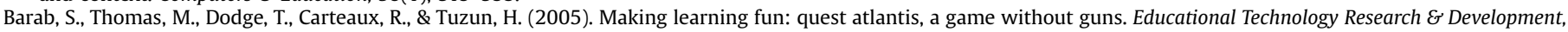
53(1), 86-107.

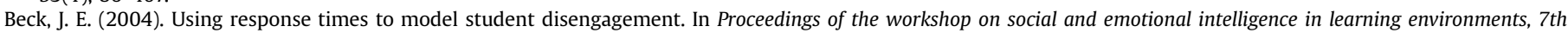
international conference on intelligent tutoring systems, Maceio, Brazil.

Boyle, E. A., Connolly, T. M., \& Hainey, T. (2011). The role of psychology in understanding the impact of computer games. Entertainment Computing, 2, 69-74.

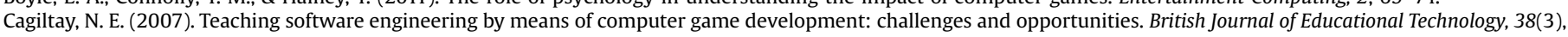
$405-415$.

Cannon, C. M., \& Bseikri, M. R. (2004). Is dopamine required for natural reward? Physiology E Behavior, 81, 741-748.

Chan, T. S., \& Ahern, T. C. (1999). Targeting motivation - adapting flow theory to instructional design. Journal of Educational Computing Research, 21(2), $152-163$.

Colby, R. S., \& Colby, R. (2008). A pedagogy of play: integrating computer games into the writing classroom. Computers and Composition, $25,300-312$.

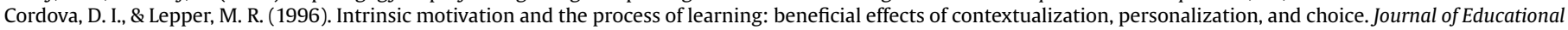
Psychology, 88, 715-730.

Csikszentmihalyi, M. (1975). Beyond boredom and anxiety. San Francisco, CA: Jossey-Bass.

Csikszentmihalyi, M. (1993). The evolving self: A psychology for the third millennium. New York: HarperCollins.

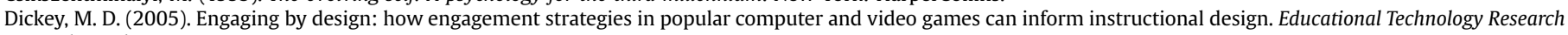
and Development, 53, 67-83.

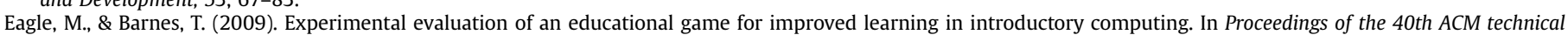
symposium on computer science education (pp. 321-325).

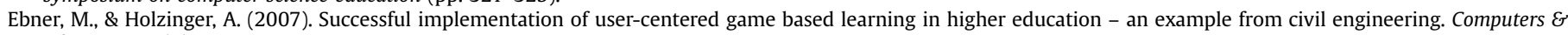
Education, 49(3), 873-890.

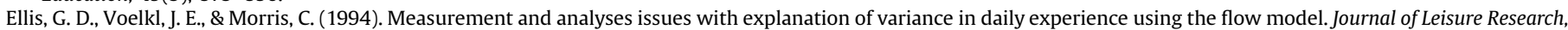
26, 337-356.

Fiorillo, C. D., Tobler, P. N., \& Schultz, W. (2003). Discrete coding of reward probability and uncertainty by dopamine neurons. Science, $299,1898-1902$.

Fu, F.-L., Su, R.-C., \& Yu, S.-C. (2009). EGameFlow: a scale to measure learners' enjoyment of e-learning games. Computers \& Education, 52, $101-112$.

Garris, R., Ahlers, R., \& Driskell, J. E. (2002). Games, motivation, and learning: a research and practice model. Simulation \& Gaming, 33, 441-467.

Griffiths, M. D. (1999). Gambling technologies: prospects for problem gambling. Journal of Gambling Studies, 1, $265-283$.

Griffiths, M. (2005). Video games and health. British Medical Journal, 331, 122-123.

Griffiths, M. D., \& Davies, M. N. O. (2002). Excessive online computer gaming: implications for education. Journal of Computer Assisted Learning, 18, 379-380.

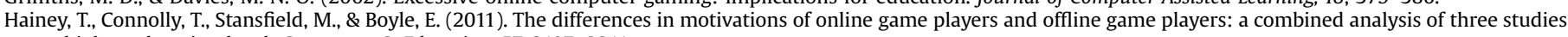
at higher education level. Computers \& Education, 57, 2197-2211.

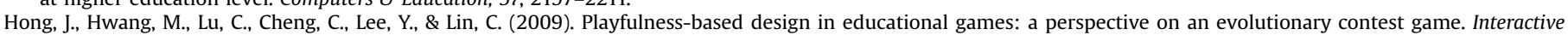
Learning Environments, 17(1), 15-35.

Howard-Jones, P. A., \& Demetriou, S. (2009). Uncertainty and engagement with learning games. Instructional Science, 37, 519-536.

Howard-Jones, P. A., Demetriou, S., Bogacz, R., Yoo, J. E., \& Leonards, U. (2011). Toward a science of learning games. Mind, Brain, and Education, 5, 3-41.

Inal, Y., \& Cagiltay, K. (2007). Flow experiences of children in an interactive social game environment. British Journal of Educational Technology, 38(3), 455-464.

Jöreskog, K., \& Sörbom, D. (1997). LISREL 8.20 for windows. Lincolnwood, IL: Scientific Software International.

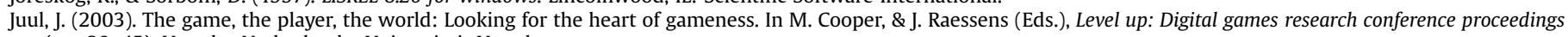
(pp. 30-45). Utrecht, Netherlands: Universiteit Utrecht.

Juul, J. (2005). Half-real: Video games between real rules and fictional worlds. Cambridge, MA: MIT Press.

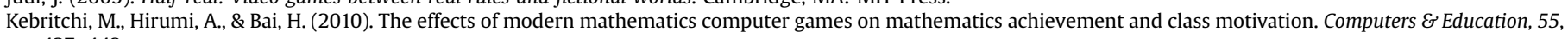
427-443.

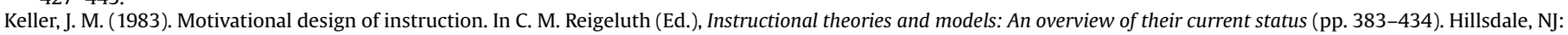
Erlbaum.

Keller, J. M. (1987). Development and use of the ARCS model of instructional design. Journal of Instructional Development, 10(3), 2-10.

Keller, J. M. (1993). Manual for instructional materials motivational survey (IMMS). Tallahassee, USA.

Keller, J. M. (2008). First principles of motivation to learn and $\mathrm{e}^{3}$-learning. Distance Education, 29(2), 175-185.

Kiili, K. (2005). Digital-game based learning: toward an experiential gaming model. Internet and Higher Education, 8, 13-24.

Kiili, K. (2007). Foundation for problem-based gaming. British Journal of Educational Technology, 38(3), 394-404.

Koob, G. F. (1992). Dopamine, addiction and reward. Seminars in Neuroscience, 4, 139-148.

Koster, R. (2005). A theory of fun or game design. Scottsdale: Paraglyph Press.

Lave, J. (1998). Cognition in practice: Mind, mathematics, and culture in everyday life. Cambridge, UK: Cambridge University Press.

Lepper, M. R., \& Cordova, D. L. (1992). A desire to be taught: instructional consequences of intrinsic motivation. Motivation and Emotion, 16(3), 187-208.

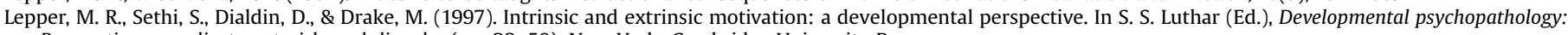
Perspectives on adjustment, risk, and disorder (pp. 23-50). New York: Cambridge University Press.

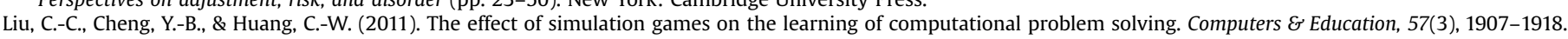

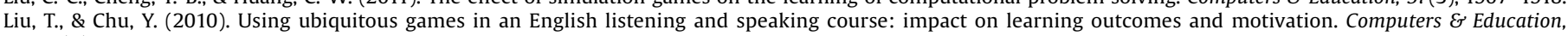
$55(2), 630-643$.

Malone, T. W. (1981). Toward a theory of intrinsically motivating instruction. Cognitive Science, 5(4), 333-369.

Meyer, K., Rasch, T., \& Schnotz, W. (2010). Effects of animation's speed of presentation on perceptual processing and learning. Learning and Instruction, 20 (2), $136-145$.

Miller, R. B., \& Backman, S. J. (2004). A model of future-oriented motivation and self regulation. Educational Psychology Review, 16, 9-33.

Moreno, R., \& Mayer, R. E. (1999). Cognitive principles of multimedia learning: the role of modality and contiguity. Journal of Educational Psychology, 91, 358-368.

Moreno, R., \& Mayer, R. E. (2005). Role of guidance, reflection, and interactivity in an agent-based multimedia game. Journal of Educational Psychology, 97, 117-128.

Northrup, C. (2001). The wisdom of menopause: Creating physical and emotional health and healing during the change. NY: Bantum Books.

Oblinger, D. (2004). The next generation of educational engagement. Journal of Interactive Media in Education, 8, 1-18.

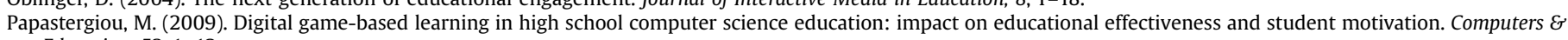
Education, 52, 1-12.

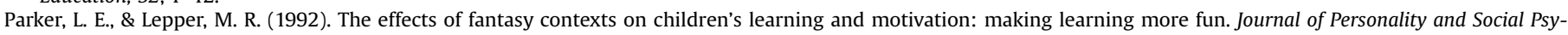
chology, 62, 625-633.

Pilke, E. M. (2004). Flow experiences in information technology use. International Journal of Human-Computer Technology, 61, 347-357.

Prensky, M. (2001). Digital game-based learning. New York: McGraw-Hill.

Prensky, M. (2003). Digital game-based learning. Computer in Entertainment, 1(1), 21.

Price, S., Rogers, Y., Scaife, M., Stanton, D., \& Neale, H. (2003). Using 'tangibles' to promote novel forms of playful learning. Interacting with Computers, 15(2), 169-185.

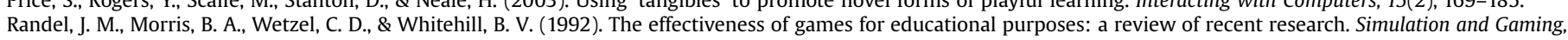
23(3), 261-276.

Raykov, T., \& Marcoulides, G. A. (2006). A first course in structural equation modeling. Mahwah, NJ: Lawrence Erlbaum Associates.

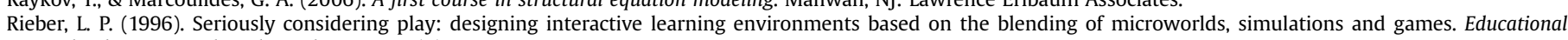
Technology Research and Development, 44(2), 43-58.

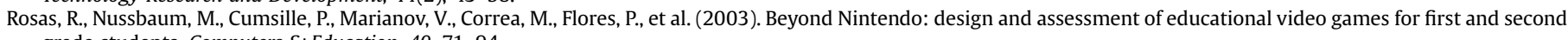
grade students. Computers \& Education, 40, 71-94.

Salen, K., \& Zimmerman, E. (2004). Rules of play: Game design fundamentals. Cambridge, MA: MIT Press.

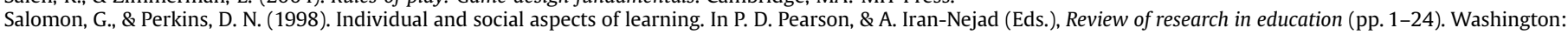
American Educational Research Association.

Schwabe, G., \& Göth, C. (2005). Mobile learning with a mobile game: design and motivational effects. Journal of Computer Assisted Learning, 21(3), 204-216. 


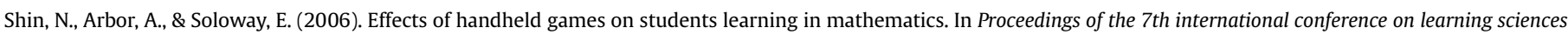
(pp. 702-708).

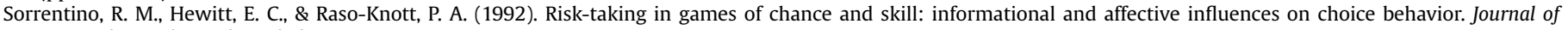
Personality and Social Psychology, 62, 522-533.

Squire, K. (2003). Video games in education. International Journal of Intelligent Simulations and Gameing, 2(1).

Sweetser, P., \& Wyeth, P. (2005). GameFlow: a method for evaluating player enjoyment in games. ACM Computers in Entertainment, 3(3).

Tan, K. H., Tse, Y. K., \& Chung, P. L. (2010). A plug and play pathway approach for operations management games development. Computers E Education, 55(1), $109-117$.

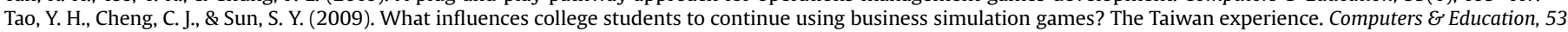
929-939.

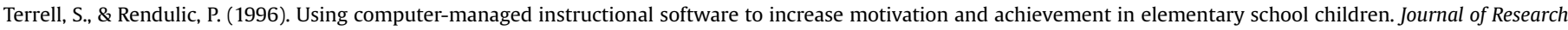
on Computing in Education, 26(3), 403-414.

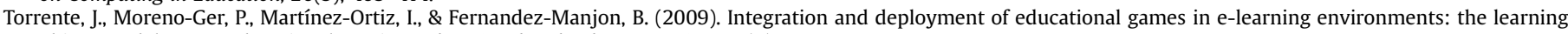
object model meets educational gaming. Educational Technology \& Society, 12(4), 359-371.

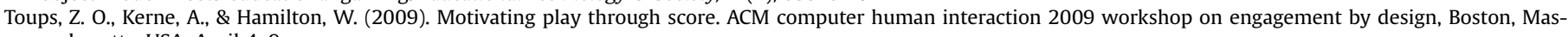
sachusetts, USA, April 4-9.

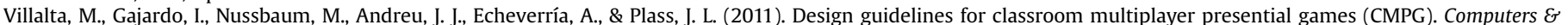
Education, 57(3), 2039-2053.

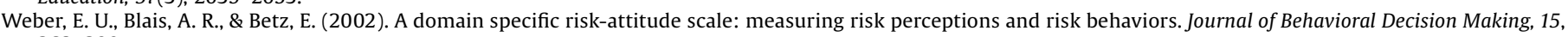
263-290.

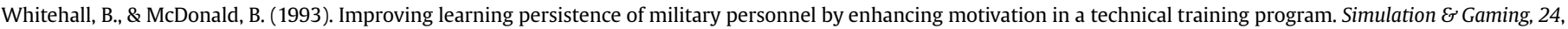
294-313. 